Gut, 1987, 28, S1, 89-94

\title{
Regulation of gene expression in pancreatic adaptation to nutritional substrates or hormones
}

\author{
H F KERN, U RAUSCH, AND G A SCHEELE \\ From the Department of Cell Biology, Philipps-University Marburg, FRG, and the Laboratory for Cell and \\ Molecular Biology, The Rockfeller University, New York, USA
}

Beginning with the work of $\mathrm{J}$ Pavlov, published in 1897 , it has been known that levels of proteases and glycosidases in pancreatic juice were regulated in direct proportion to levels of protein and starch, respectively, in the diet. Pancreatic adaptation to nutritional substrates has been extensively studied at the level of tissue content ${ }^{1}$ and at the level of biosynthesis of specific enzymes. ${ }^{2-5}$ From a study of normal, diabetic, and insulin-treated rats, Desnuelle first suggested that insulin is involved in the adaptation of amylase biosynthesis in response to changes in carbohydrates in the diet. Despite numerous studies however, which have documented the predominant role of secretin and cholecystokinin (CCK) in stimulating fluid, bicarbonate and enzyme secretion in the exocrine pancreas, the role of these peptide hormones in the regulation of protein synthesis and pancreatic adaptation was, until recently, largely unappreciated.

Because of rapid dedifferentiation of pancreatic acinar cells placed in tissue culture, it has not been possible to study under in vitro conditions, adaptive changes on normal isolated cells. By use of continuous intravenous infusion of synthetic caerulein and secretin in optimal concentrations in the conscious rat we have been able to determine the limits of biochemical response to these hormones. ${ }^{6-8}$ After removal of the pancreas and incorporation of radiolabelled amino acids in the pancreatic lobules under in vitro conditions, separation of proteins by two dimensional IEF/SDS-gel electrophoresis has allowed a study of individual rates of synthesis for each of the exocrine products synthesised in the differentiated gland. An initial study ${ }^{5}$ varying the content of protein and carbohydrate in the diet between 0 and $82 \%$, respectively, keeping lipid constant, indicated that amylase and the majority of protease zymogens were synthesised in direct proportions to the nutritional substrates (Fig. 1).

Caerulein infusion in the conscious rat resulted in both coordinate and anticoordinate regulation of

Address for correspondence: Prof Dr H F Kern, Institut für Zytobiologie und Zytopathologie, Robert-Koch-StraBe S, D-3550 Marburg/Lahn, Federal Republic of Germany.

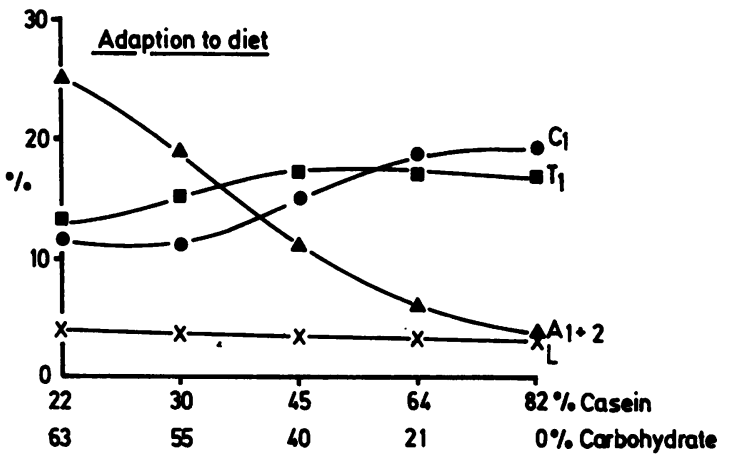

Fig. 1 Fractional rate of synthesis of lipase (L), two forms of amylase ( $A$ ) anionic forms of trypsinogen (TI) and chymotrypsinogen (C1) as a function of feeding diets containing variable amounts of protein (casein) and carbohydrate for a period of 12 days. $22 \%$ casein plus $63 \%$ carbohydrate is the standard laboratory chow. For details of experiments and findings on other enzymes see ref. 5.

protein synthesis. ${ }^{\circ}$ Beginning with a latent period of one to two hours synthesis of the majority of protease forms (anionic trypsinogen forms 1 and 2, anionic (C1) and cationic (C2) forms of chymotrypsinogen, anionic proelastase (PE1), and the group of procarboxypeptidase A and B (PCP A \& B) was increased while the synthesis of amylase forms 1 and 2 was decreased (Fig. 2). Synthesis of lipase and cationic trypsinogen (T3) was not altered. Anticoordinate changes in protein synthesis were also observed with secretin stimulation but the period of latency was longer (two to three hours) and the pattern of response in the synthesis of some enzymes was different. ${ }^{10}$ In this case the synthesis of lipase and cationic proelastase (PE2) was increased and the synthesis of amylase forms 1 and 2 was decreased (Fig. 3).

Thus, in the rat it appears that synthesis of functional groups of enzymes (proteases, lipase, amylases) is regulated by specific hormones (CCK, secretin, insulin), respectively. In order to compare 


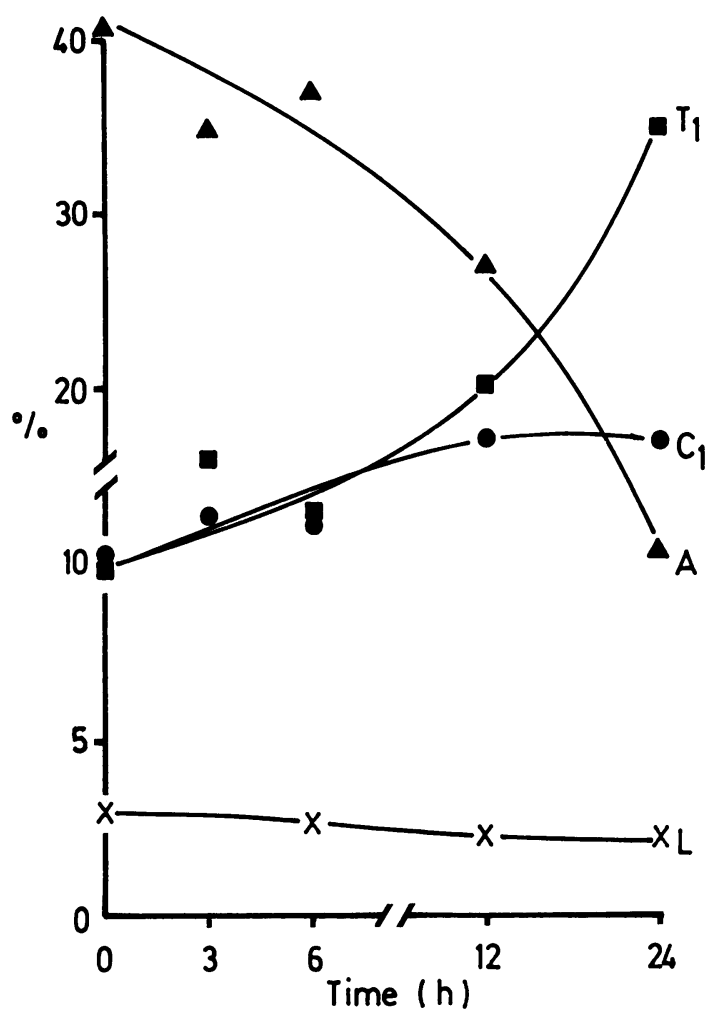

Fig. 2 Fractional synthetic rates of the same enzymes as in Fig. 1 as a function of time during in vivo infusion of 0.25 $\mu \mathrm{g} / \mathrm{kg} / \mathrm{g}$ synthetic caerulein. Radioactive proteins contained in cell homogenates were separated by two-dimensional IEFSDS gel electrophoresis and were expressed as a fractional per cent of radioactivity incorporated into all exocrine proteins.

the patterns of regulation of protein synthesis during hormonal stimulation with those observed during dietary adaptation, it was necessary to compare exogenous administration of hormones with conditions under which endogenous release of hormones is obtained. This can be achieved by either feeding a single dose of a new synthetic proteinase inhibitor (Camostate, FOY 305) which releases CCK by interfering with feedback regulation of active trypsin on CCK release in the duodenum. A second experimental approach involves prolonged fasting (72 hours), followed by refeeding, which also stimulates prolonged CCK release. Oral feeding of a single dose of $50 \mathrm{mg} / \mathrm{kg}$ FOY 305 resulted in a 10 -fold increase in plasma CCK-levels which persisted for three to six hours. ${ }^{11}$ Total rate of protein synthesis increased during this time period by 80 to $90 \%$ above control levels and returned to normal by nine hours. Changes in individual rates of protein synthesis were observed

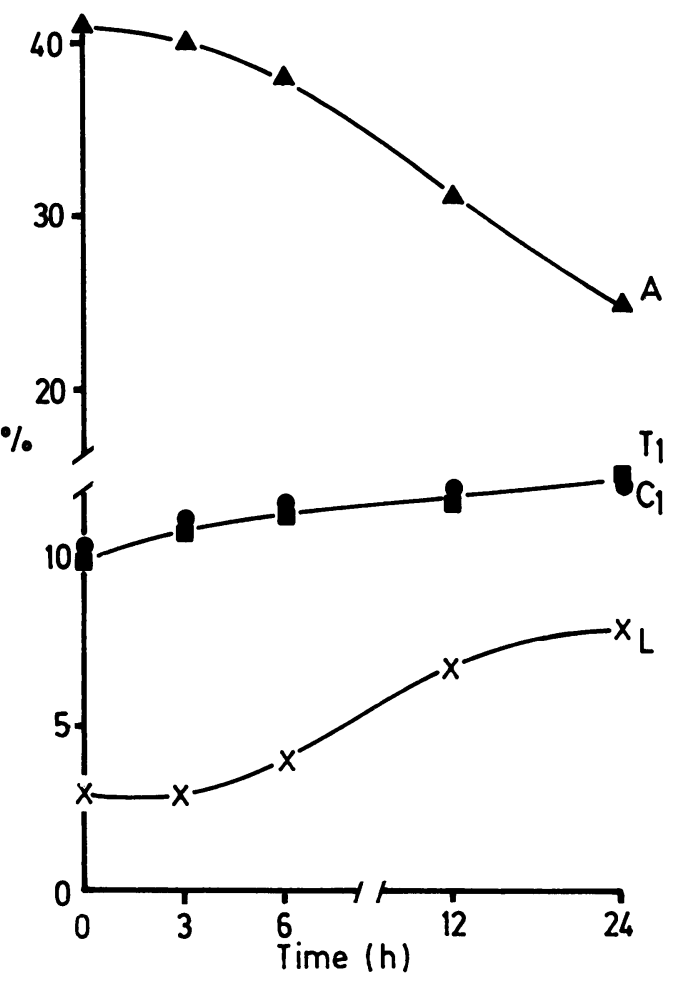

Fig. 3 Fractional rate of synthesis of four major pancreatic enzymes as a function of time during in vivo infusion of $4.64 \mu \mathrm{g} / \mathrm{kg} / \mathrm{h}$ synthetic secretin. Data are given as in Fig. 2 .

beginning at nine hours after FOY administration. The changes were similar to the ones previously observed with caerulein infusion (increase in the majority of protease forms, no change in lipase, and a decrease in amylase).

After endogenous release of CCK, however, increase in the synthesis of anionic chymotrypsinogen (C1) was greater than that observed with anionic trypsinogen form 1 and $2 .{ }^{12}$ The opposite had been observed with caerulein infusion. ${ }^{9}$ It is noteworthy that a similar pattern of response as observed after FOY feeding has been found with the fastingrefeeding protocol..$^{13}$

The resolution obtained in the study of 16 exocrine products and in the pattern of their biosynthesis has allowed us to compare in detail changes observed during dietary adaptation with changes observed during hormonal stimulation. The pattern of response found during administration of a high protein diet (increase in $\mathrm{Cl}>\mathrm{T} 1,2>\mathrm{C} 2>\mathrm{PE} 1>\mathrm{PCPA}+\mathrm{B}$, no change in $\mathrm{L}$ or $\mathrm{T} 3$, decrease in $\mathrm{A} 1=\mathrm{A} 2$ ) was largely identical to that observed after endogenous release of CCK and similar to that observed during caerulein stimulation. Although less well studied, changes in 
protein synthesis seen in the rat during administration of a high fat diet (increase in lipase and colipase synthesis) correlated reasonably well with changes seen during secretin infusion (personal communication).$^{10}$ Thus, in the rat it appears that pancreatic adaptation to changes in nutritional substrates in the diet is regulated through specific hormones. This, however, might not be true for other species and further work is needed to investigate the response of protein synthesis to specific hormones in other species.

Elucidation of the molecular mechanisms which regulate anticoordinate changes in protein synthesis in the exocrine pancreas in response to hormone stimulation is of fundamental importance in the understanding of dietary adaptation. From the work of a number of laboratories, the basic steps in gene expression are now understood. Transcription of a specific gene by RNA polymerase II results in the formation of a primary RNA transcript, which together with a wide variety of nuclear RNA transcripts constitutes heterogenous RNA, so called because of the variation observed in both nucleotide length and sequence specificity. Within the nucleus, the primary RNA transcript is modified or processed largely through (a) the removal of intron sequences by splicing mechanisms and (b) the addition of a poly (A) tail to the $3^{\prime}$ terminus. Processed mRNA is transported from the nucleus into the cytoplasm where, after functional binding of $40 \mathrm{~S}$ and $60 \mathrm{~S}$ ribosomal subunits, its coding sequence is translated into protein. ${ }^{14}$ Regulation of gene expression may therefore occur at different levels including (1) transcription, (2) RNA processing, (3) mRNA transport (4) efficiency of mRNA translation, or (5) mRNA sequestration or degradation.

Although the information contained in the genetic code flows from DNA to RNA to protein, the events which regulate gene expression involve the interaction of regulatory proteins with specific nucleotide sequences on DNA. ${ }^{15}$ Thus synthesis of heterogenous RNA from limited regions of DNA is catalysed by the enzyme RNA polymerase II. This multimeric enzyme initiates the transcription process after binding to a specific region of DNA termed the promoter or TATA sequence, which usually resides 30 nucleotides upstream from the nucleotide at which transcription begins, the mRNA start site. After unwinding the DNA helix at the promoter site, RNA polymerase moves along the DNA and polymerises a single stranded mRNA sequence through the sequential addition of individual ribonucleotides. The efficiency of gene transcription initiated at the promoter site, however, is regulated by enhancer sequences, which usually reside further upstream in the $5^{\prime}$ flanking region of genes. Enhancer elements occur in two types, one of which regulates the expression of genes in specific tissues and the other which modulates gene expression in response to hormones. ${ }^{16}$

An understanding of how hormones regulate gene expression is largely confined to the action of steroid hormones. Studies from several laboratories have indicated that steroid hormone receptor proteins are DNA binding proteins. ${ }^{17}$ Subdomains of the steroid receptor include a hormone binding site and a DNA binding site which interacts with specific nucleotide sequences in the enhancer regions of several genes whose expression is regulated by steroid hormones. ${ }^{17}$ The available evidence indicates that steroid hormones regulate gene expression at the level of transcription. In this case the changes observed in protein synthesis correlated with significant changes in mRNA levels and these in turn were correlated with changes in transcription rates of specific genes as determined by the use of complementary DNA probes. $^{18}$

In contrast little is known regarding the molecular mechanisms involved in gene expression by peptide hormones. In this area we have focused our research in the past years on studies relating to CCK and secretin stimulation in the rat exocrine pancreas. A consecutive study analysing functional mRNA concentrations in an in vitro translation system demonstrated that pronounced changes in individual enzyme biosynthesis were not accompanied by changes in levels of mRNA at least during the initial six hours of caerulein stimulation. ${ }^{19}$ Consequently, we have suggested that during the early periods of caerulein stimulation, the anticoordinate changes observed in protein synthesis occur at the level of efficiency of mRNA translation. With continuation of caerulein stimulation for 12 or 24 hours, minor changes were observed in mRNA levels which paralleled those observed in protein synthesis. ${ }^{20}$ Further research is needed to determine whether changes in mRNA levels during these late periods or after chronic hormone administration for several days are mediated by changes in transcription rates, mRNA turnover rates or both. ${ }^{21}$ Thus, with caerulein stimulation, there appears to be at least two distinct and overlapping phases in the regulation of gene expression. It is impressive that the anticoordinate changes observed in protein synthesis in both phases are similar and that regulations which occur in the second period serve to augment those occurring in the initial period. Sequential and overlapping regulation in this manner represents, at the biochemical level, increased commitment to adaptive changes.

The observation of a regulation of protein synthesis in the absence of changes in mRNA levels by peptide hormones poses the question about the regulatory mechanisms. Because of the relatively long half lives of mRNAs for exocrine pancreatic products, four to 
(a)

5 'Noncoding sequences

Rat trypsinogen $(\mathrm{pl}=4 \cdot 3$ )

Dog trypsinogen $(\mathrm{pl}=4 \cdot 7)$

(b)

Dog trypsinogen $(\mathrm{pl}=8 \cdot 1)$

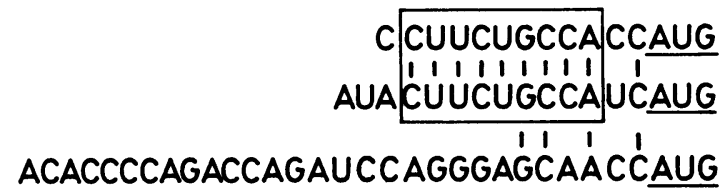

Potential stem-loop structure in $3^{\prime}$ end of $18 \mathrm{~s}$ rRNA

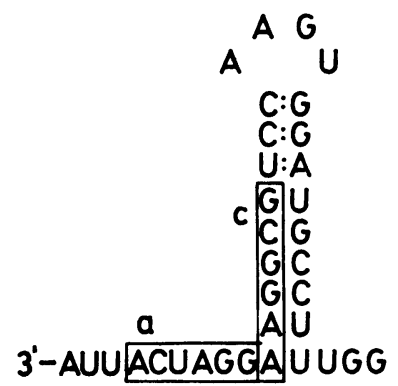

(c)

Potential hybridisation of $5^{\prime}$ noncoding sequences to $18 \mathrm{~s}$ rRNA

\section{AUACUUCUGCCAUCAUG $::::::$ : : : \\ 3 AUU ACUAGGAAGGCGUCC $\longrightarrow$ $:::::$}

Dog anionic trypsinogen mRNA

Eukaryotic 18S rRNA

Dog cationic trypsinogen mRNA

Fig. 4 Comparison of $5^{\prime}$-noncoding sequences in $m R N A$ of rat and dog trypsinogen isoenzymes (anionic and cationic form) in@and formation of a potential stem loop structure in the $3^{\prime}$ end of $18 S$ rRNA (shown in (b)). Potential hybridisation of $5^{\prime}$-nontranslated region of trypsinogen isoenzyme $m R N A$ with $18 S \mathrm{~S} R \mathrm{NA}$ is shown in (C).

six hours, it is reasonable to expect that the early changes observed in protein synthesis, minutes to hours, are mediated at the translational level. Little is known at present, however, regarding the molecular mechanism by which changes in efficiency of mRNA translation may occur in the cell. Presumably such changes are mediated at the level of efficiency in the initiation of mRNA translation, which represents the rate limiting step in protein synthesis. Changes at this level may involve nucleotide signals in the $5^{\prime}$-nontranslated regions of $m R$ NAs and the interaction of these signals or sequences with either regulatory proteins or regulatory RNA molecules.

The majority of mRNAs coding for pancreatic enzymes in the rat and dog have now been sequenced $^{16}$ and it is therefore possible to analyse mechanisms which may be responsible for modulation of initiation of mRNA translation. A comparison of the 5'-non-translated sequences of anionic and cationic trypsinogen mRNAs has suggested a mechanism by which the synthesis of the anionic but not the cationic isoenzyme is increased during caerulein stimulation. ${ }^{22}$ The 5 -non-translated regions of dog and rat anionic trypsinogen mRNAs are short (14 and 12 nucleotides, respectively) and show a region of conserved sequence involving nine contiguous and identical residues (Fig. 4). In contrast, this conserved sequence was not observed among 29 nucleotides in the $5^{\prime}$-non-translated region of cationic trypsinogen mRNA. The conserved element in the two anionic trypsinogen mRNAs also showed potential base pairing to a region at the $3^{\prime}$ end of $18 \mathrm{~S}$ ribosomal RNA which exists in a stem-loop structure (Fig. 4). This region of the 18S rRNA is known to occur near the site of initiation of mRNA translation. The initiation process in eukaryotic cells involves at 


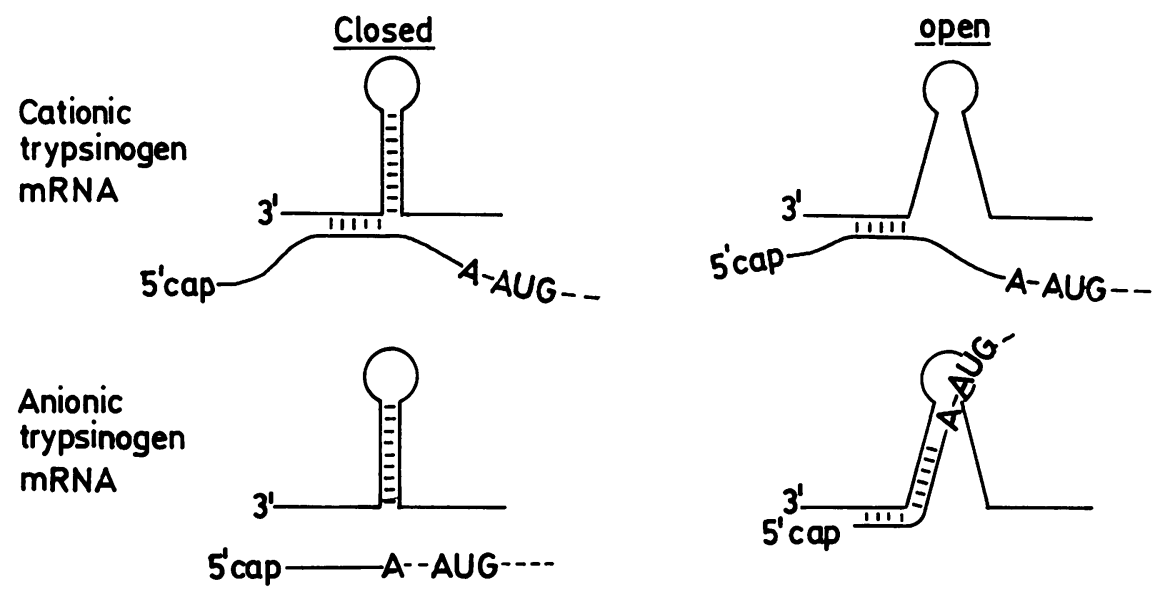

Fig. 5 Hypothetical role of stem loop structure at the $3^{\prime}$ terminus of $18 S \mathrm{rRNA}$ in the regulation of protein synthesis. For details see text.

least two interactions between mRNA and the small (40S) ribosomal subunit: (a) binding of a protein complex associated with the $5^{\prime}$ cap of mRNA to the ribosomal subunit and (b) binding of the AUG initiation codon to the UAC anticodon of the initiation methionine tRNA, which is associated with activated $40 \mathrm{~S}$ subunits. We have proposed ${ }^{22}$ that base pair interactions between anionic trypsinogen mRNA and 18S rRNA represent, under certain circumstances, a third interaction between mRNA and the 40S ribosomal subunit. Because the stem loop structure in the 18S rRNA exists in the closed configuration under basal conditions as judged by analysis of isolated $40 \mathrm{~S}$ subunits, we have hypothesised that during hormonal stimulation, the stem loop is disrupted. In the open configuration, potential base pairing may occur between anionic trypsinogen mRNA and 18S rRNA, which may serve to promote mRNA alignment and facilitate the initiation of mRNA translation (Fig. 5). In contrast, alternative configurations in this region of $18 \mathrm{~S}$ rRNA will have little effect on the binding of cationic trypsinogen mRNA. Under conditions in which the stem loop is open, the efficiency of translation of anionic but not cationic trypsinogen mRNA may increase, resulting in increased synthesis of anionic but not cationic trypsinogen.

\section{References}

1 Grossman MJ, Greengard H, Ivy AC. The effect of dietary composition on pancreatic enzymes. Am J Physiol 1943; 138: 676-82.

2 Desnuelle P, Reboud IP, Ben Abdeljlil A. Influence of the composition of the diet on the enzyme content of rat pancreas. In: Cameron MP, de Reuck AVS, eds. Ciba
Foundation Symposium on the exocrine pancreas. Boston, MA: Little, Brown, 1962: 90-114.

3 Dagorn IC, Lahaie RG. Dietary regulation of pancreatic protein synthesis. I. Rapid specific modulation of enzyme synthesis by changes in dietary composition. Biochim Biophys Acta 1981; 654: 111-18.

4 Lahaie RG, Dagorn IC. Dietary regulation of pancreatic protein synthesis. II. Kinetics of adaptation of protein synthesis and its effect on enzyme content. Biochim Biophys Acta 1981; 654: 119-23.

5 Schick J, Verspohl R, Kern HF, Scheele GA. Two distinct adaptive responses in the synthesis of exocrine pancreatic enzymes to inverse changes in protein and carbohydrate in the diet. Am J Physiol 1984; 247: G611-6.

6 Bieger W, Martin-Achard A, Bassler M, Kern HF. Studies on intracellular transport of secretory proteins in the rat exocrine pancreas. IV. Stimulation by in vivo infusion of caerulein. Cell Tissue Res 1976; 165: 43553.

7 Bieger W, Seybold J, Kern HF. Studies on intracellular transport of secretory proteins in the rat exocrine pancreas. V. Kinetic studies on accelerated transport following caerulein infusion in vivo. Cell Tissue Res 1976; 170: 203-19.

8 Rausch U, Vasiloudes $P$, Rüdiger $K$, Kern HF. In vivo stimulation of rat pancreatic acinar cells by infusion of secretin. I. Changes in enzyme content, pancreatic fine structure and total rate of protein synthesis. Cell Tissue Res 1985; 242: 633-9.

9 Schick J, Kern HF, Scheele GA. Hormonal stimulation in the exocrine pancreas results in coordinate and anticoordinate regulation of protein synthesis. $J$ Cell Biol 1984; 99: 1569-74.

10 Rausch U, Vasiloudes P, Rüdiger K, Kern HF. In vivo stimulation of rat pancreatic acinar cells by infusion of secretin. II. Changes in individual rates of enzyme and isoenzyme biosynthesis. Cell Tissue Res 1985; 242 : $641-4$.

11 Rausch U, Adler G, Weidenbach $\mathrm{H}$, et al. Stimulation of pancreatic secretory process in the rat by low-molecular 
weight proteinase inhibitor. I. Dose-response study on enzyme content and secretion, cholecystokinin release and pancreatic fine structure. Cell Tissue Res 1987; 247 : 187-93.

12 Rausch U, Adler G, Weidenbach $\mathrm{H}$, et al. Stimulation of pancreatic secretory process in the rat by low-molecular weight proteinase inhibitor. II. Regulation of total protein and individual enzyme biosynthesis. Cell Tissue Res 1987; 249: 63-7.

13 Rausch U, Kern HF. Adaptation of pancreatic protein synthesis and secretion to prolongued fasting and refeeding in the rat. Cell Tissue Res 1987; (Submitted for publication).

14 Darnell IE. Variety in the level of gene control in eukaryotic cells. Nature 1982; 297: 365-71.

15 Dynan WS, Tjian R. Control of eukaryotic messenger RNA synthesis by sequence-specific DNA-binding proteins. Nature 1985; 316: 774-8.

16 Scheele GA. Regulation of gene expression in the exocrine pancreas. In: Go VLW et al, eds. The exocrine pancreas; biology, pathobiology and diseases. New York: Raven Press, 1986: 55-67.

17 Scheidereit C, Geisse S, Westphal HW, Beato M. The glucocorticoid receptor binds to defined nucleotide sequences near the promotor of mouse mammary tumour virus. Nature $1983 ; 304: 749-52$.

18 von der Ahe D, Janich S, Scheidereit C, Renkawitz R, Schütz G, Beato M. Glucocorticoid and progesterone receptors bind to the same sites in two hormonally regulated promotors. Nature 1985; 313: 706-9.

19 Wicker C, Puigserver A, Rausch U, Scheele GA, Kern HF. Multiple-level caerulein control of the gene expression of secretory proteins in the rat pancreas. Eur $J$ Biochem 1985; 151: 461-6.

20 Steinhilber W, Poensgen J, Rausch U, Kern HF, Scheele GA. Translational control of amnionic trypsinogen and amylase synthesis by caerulein stimulation in the rat pancreas. Mol Cell Biol 1987; (Submitted for publication).

21 Renaud W, Giorgi D, Iovanna I, Dagorn IC. Regulation of concentrations of mRNA for amylase, trypsinogen I, and chymotrypsinogen $\mathbf{B}$ in rat pancreas by secretagogues. Biochem $J$ 1986; 235: 305-8.

22 Pinsky SD, LaForge KS, Scheele GA. Differential regulation of trypsinogen mRNA translation: fulllength mRNA sequences encoding two oppositely charged trypsinogen isoenzymes in the dog pancreas. Mol Cell Biol 1985; 5: 2669-76. 